\title{
The Web Experimental Psychology Lab: Five years of data collection on the Internet
}

\author{
ULF-DIETRICH REIPS \\ University of Zurich, Zurich, Switzerland
}

\begin{abstract}
In fall 1995, the worldwide-accessible Web Experimental Psychology Lab (http://www.genpsylab. unizh.ch) opened its doors to Web surfers and Web experimenters. It offers a frequently visited place at which to conduct true experiments over the Internet. Data from 5 years of laboratory running time are presented, along with recommendations for setting up and maintaining a virtual laboratory, including sections on the history of the Web laboratory and of Web experimenting, the laboratory's structure and design, visitor demographics, the Kids' Experimental Psychology Lab, access statistics, administration, software and hardware, marketing, other Web laboratories, data security, and data quality. It is concluded that experimental data collection via the Internet has proven to be an enrichment to science. Consequently, the Web Experimental Psychology Lab will continue and extend its servicesto the scientific community.
\end{abstract}

In September 1995, the Web Experimental Psychology $\mathrm{Lab}^{1}$ (the Web Lab) opened its doors to Web surfers and has been providing its services since. The opening marked the beginning of a new era of on-line data collection, since it became possible to conduct psychological experiments via the World-Wide Web (WWW) in a freely accessible laboratory. Several tens of thousands of participants have visited the University of Tübingen based virtual laboratory (now at the University of Zurich). A large proportion of these visitors have taken part in one of the more than three dozen Web experiments that have been conducted in the laboratory by several researchers from various locations around the world.

This virtual laboratory is modeled as a metaphor of a real laboratory. It contains various "rooms," and several studies are run at the same time. Participants arrive at a main entry point, are greeted and given information, participate in one or more Web experiments, and then leave. Some are contacted later for feedback or because they won a reward; some return for more information or to participate in another study.

\section{A BIT OF HISTORY}

The laboratory's history goes back to the time soon after the advent of the WWW. In 1994, the idea was born, and preliminary work began. Web pages were assembled using some of the very first HTML editors available on the Macintosh, such as Arachnae and HTML Web Weaver. A Web server had to be established and had to be connected

I thank Tom Buchanan, Gregory Francis, Mike Mangan, and Jonathan Vaughan for helpful comments on earlier versions of this article. Correspondence concerning this article should be addressed to U.-D. Reips, Allgemeine und Entwicklungspsychologie,Universität Zürich, Attenhoferstr. 9, CH-8032 Zürich, Switzerland (e-mail: ureips@genpsy.unizh.ch). to the Internet. Scripts for experimental procedures were written and tested. Links were established on other Web sites. All these tasks had to be accomplished in a constantly and rapidly changing Internet environment, in which today's search opportunities were not available yet (intelligent search engines, such as www.google.com, were not available before 1997). In addition, the methodology of what the Web Lab had been built for, Web experiments, had to be explored and developed.

\section{The History of Web Experiments}

The history of Internet-based research in general can be described in terms of six steps: (1) introduction of computers, (2) local area networking, (3) wide area networking, (4) the introduction of HTML, (5) beginning of on-line data collection, and (6) establishment of on-line laboratories (Musch \& Reips, 2000).

In the 1970 s, experimental laboratory research was revolutionized by the introduction of computers (e.g., Connes, 1972; Hoggatt, 1977). Among the advantages of using computers was the ease of data entry, data storage, and statistical analysis. Intelligent procedures added adaptivity and interactivity to the research process. Computerized research allowed for standardized and controlled presentation of stimuli, item-branching capabilities, elimination of missing responses, elimination of transcription costs and errors, accurate measurements of response times, reduction of the tendency to respond in a socially desirable way (e.g., Booth-Kewley, Edwards, \& Rosenfeld, 1992), and avoidance of experimenter biases and demand characteristics (Hewson, Laurent, \& Vogel, 1996; Reips, 2000).

To extend human experimental research in the behavioral sciences beyond single PCs, local computer networks have been used for the collection of data (Hoffman \& MacDonald, 1993). Because the use of computers is a widely used method for conducting research in the behavioral 
sciences nowadays and networked data collection had been explored, the groundwork had largely been prepared for the Internet revolution in experimental research.

Interactive forms (or fill-out forms) were first introduced with HTML 2.0 in 1994. For the first time, the reader of a Web document could communicate back to the server. WWW users could choose to become participants in Web experiments and could send experimental data back to the experimenter. It was soon discovered that using the Internet to conduct research offered several advantages over traditional research practices (Buchanan \& Smith, 1999; Hewson et al., 1996; Reips, 1995), with certain particularly interesting advantages for experimental research (see Reips, 2000, for a summary). Use of this world-wide network for experimental research therefore became the logical next step in the process that began with the first experiments on stand-alone computers.

Although some Web experiments are conducted as undercover experiments ${ }^{2}$ (Hänze \& Meyer, 1997), openly accessible Web experiments were conducted earlier, more often, and with fewer ethical concerns (Musch \& Reips, 2000). Naturally, only open Web experiments can be run in a virtual laboratory.

In late 1994, during the planning phase for what later became the Web Experimental Psychology Lab, an Internet scan for Web experiments produced no results. However, before the Web Experimental Psychology Lab went on line with its first two experiments in September 1995, a few experiments had already been conducted on the WWW (Krantz, Ballard, \& Scher, 1997; Musch \&
Reips, 2000). The Web experiments with which the Web Experimental Psychology Lab opened its doors were the first Web experiments with a between-subjects design. These Web experiments were designed to test hypotheses on the cognitive consistency of causal mechanisms and on the influence of causal models on performance in the Wason selection task (Reips, 1996a, 1996b, 1997b; Wason, 1968). Both Web experiments are still accessible in the Web lab's archive. ${ }^{3}$ Between-subjects designs require random assignment of participants to experimental conditions, which can be realized in Web experiments through the use of small helper programs or scripts called CGIs (Kieley, 1996; Morrow \& McKee, 1998; Reips, 1996b, 1997b, in press-b), Javascript, Java, or the "birthday technique" (e.g., Birnbaum, 1999), by which assignment of participants to conditions is achieved quasi-randomly through clicking on the date of one's birthday. The Web Experimental Psychology Lab actively invites participation by or cooperation with other researchers conducting Web experiments that can be hosted by the lab.

\section{THE WEB LAB'S “ROOMS”}

The Web Experimental Psychology Lab is partitioned into two language versions, which both contain the following eight sections (see Figure 1): (1) the main room or entrance hall, leading into all other rooms, (2) experimental rooms with Web experiments currently being conducted, (3) an archive with information on and examples of past Web experiments, (4) a methodological sec-

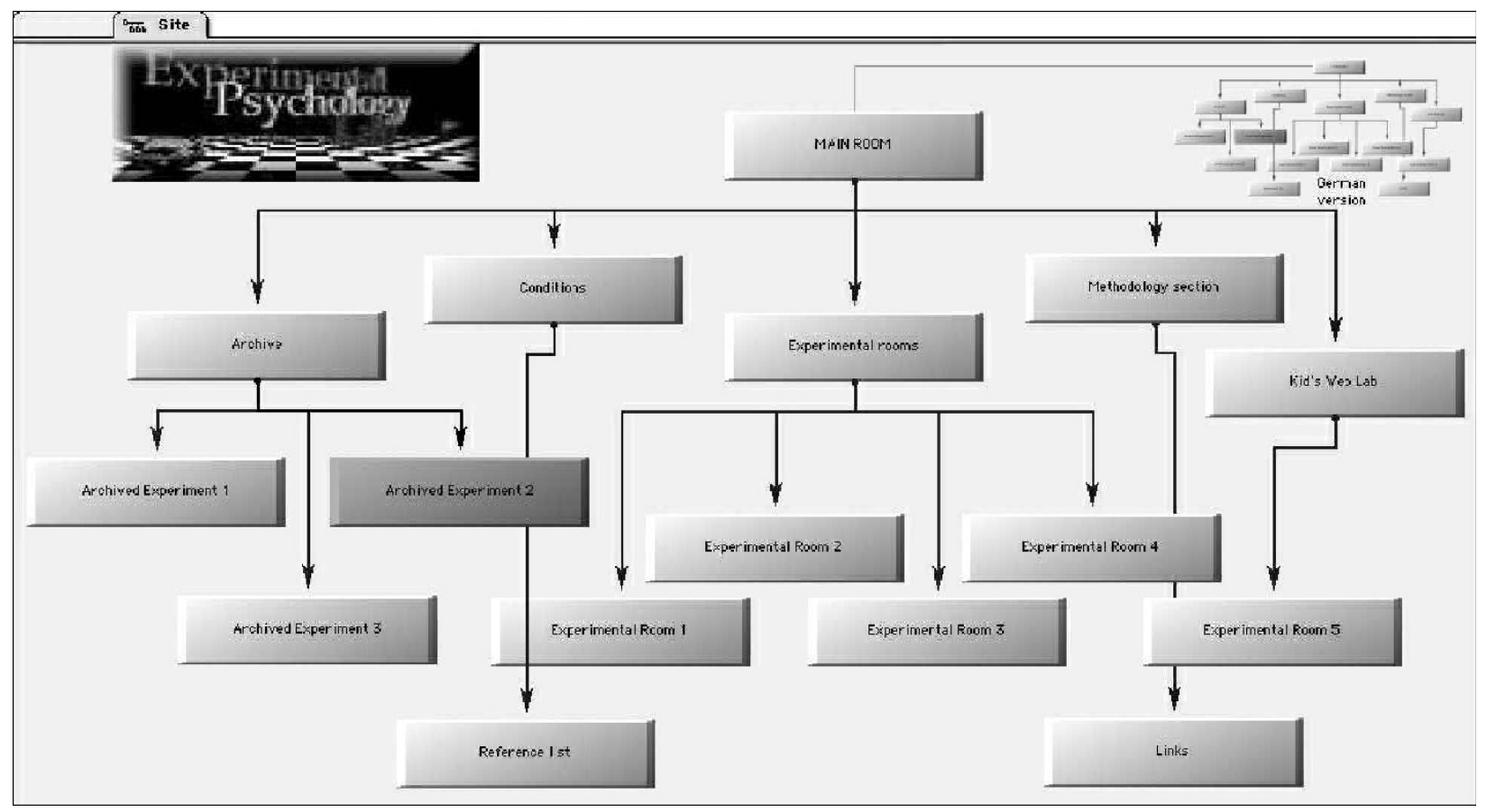

Figure 1. Logo and map of the Web Experimental Psychology Lab. 
tion explaining Web experiments and their advantages and disadvantages, (5) a reference list of publications on data collection via Internet (Internet Science), (6) links to other, similar Web sites, (7) conditions for use of the Web Lab, ${ }^{4}$ and (8) the Kid's Experimental Psychology Lab. ${ }^{5}$

Until July 2000, there were additional "animated" versions of the main pages, containing a graphically richer design. However, these Web pages were abandoned for leaner administration.

\section{Main Room and Archive}

The main page contains the Web experiments currently being conducted, in reverse chronological order. Each experiment has its own slot, containing the following items: a clickable image leading to the experiment's introductory page, information about the goal or theme of the experiment, the researchers' names and their institutional affiliations, the principal author's e-mail address, approximate duration of the experiment, the date the experiment was first listed in the Web Experimental Psychology Lab, and a mailto-hyperlink for contacting the principal researcher and the Web Lab administration in case the Web experiment cannot be accessed.

Past Web experiments are listed in the archive, often along with mock-up versions of the experiments, descriptions of their theoretical as well as technical backgrounds, and their results. Since these archived Web experiments can be linked to and from publicationsin on-line journals, they can show more clearly than written descriptions how an experiment looked. Thereby, the Web Experimental Psychology Lab is contributing to a transparent and highly integrated scientific process (Reips, 1997a).

Beginning with a place in the "Top Ten" on-line sites list of the German national magazine Der Spiegel in January 1996, the Web Experimental Psychology Lab received a number of awards. These awards are also displayed on the main page, serving the function of conveying the message to visitors that this Web site might be worth exploring. (It should be mentioned that there has been an increasing tendency to give out these awards in order to get the awarding organization's Web site linked on the awardreceiving Web site.) Some of the awarding organizations display written reviews or summaries of the Web Experimental Psychology Lab on their Web sites. The following is an example from the Encyclopaedia Britannica, which gave a two-star rating (three stars are the maximum):

Online opportunity for participation in psychological experiments. Solicits commentaries on current experiments and submission of new designs. Also discusses the pros and cons of collecting data via the Internet. This site provides a chance for young students and general users to learn about experimental design and data collection and to take part in real research. It may also benefit researchers whose sampling needs are not restrictive.

Such reviews might attract visitors who, after reading the review, can follow a hyperlink that leads them directly into the Web Experimental Psychology Lab's entrance hall.

\section{The Methodological Section}

There are a number of reasons why it is advantageous to conduct experiments on the Web. Reips (2000) describes 18 advantages of Web experiments, when compared with laboratory experiments-among them, cost savings, generalizability, ease of access to a demographically and culturally diverse participant population and to very rare, specific participant populations, completely voluntary participation, detectability of motivational confounding, the ability to assess the number of nonparticipants, and ease of access for participants. Reips (2000) also mentions potential methodological problems, such as self-selection, experimental control, multiple submissions, drop out, reduced or absent interaction with participants, and limited external validity. The Web Lab contains a section that serves as a forum for discussion of these issues. Here, Web experimenters can find information about techniques that help ensure quality in data collection over the Internet. Such techniques include the following: warm-ups, high hurdles, subsampling, multiple site entry, passwords, controlling for multiple submissions, controlling for motivational confounding, nonobvious file naming, providing contact information, randomization, pseudorandomization, and drop-out reducing design. For an introduction to these techniques see Reips (1997b, 2000, in press-b), and see Janetzko (1999) for a review of useful statistical applications.

\section{Conditions for Use of the Web Lab}

The Web Experimental Psychology Lab is open to everyone who wants to conduct an experimental study. To ensure a high standard for the quality of the scientific research conducted, experimenters are encouraged to make sure that their proposed work meets the following criteria prior to submitting it to the Web site.

1. Studies must be an experiment or at least have an experimental component.

2. Studies must be designed primarily to advance scientific, not market, knowledge.

3. Participants must not be deceived about the purpose of the study.

4. Research participants must receive some type of debriefing.

5. Participants should be offered an incentive for participating.

6. Documentation of Web experiments must be provided to the Web Experimental Psychology Lab by study authors. The documentation is linked from or placed in the Web Lab's archive either during the experiment or after its completion.

The above requirements were developed to ensure compliance with general ethical guidelines for psychological research. The last requirement was formulated with the intention of creating an archive that contains all the experiments ever run in the Web Lab, plus their documentation.

Guidelines for conducting Web experiments can be found in Birnbaum (2000) and Reips (1997b, 2000). 


\section{An Offspring:}

The Kids' Experimental Psychology Lab

As the number of Web experiments in developmental psychology increased, we saw the opportunity to open a laboratory designed to attract juveniles and children (for a brief discussion of issues in on-line research with children, see Reips, 1999). The Kids' Experimental Psychology Lab opened in July 2000, beginning with two Web experiments in English and German. One of the Web experiments was on causal attributions made under the impression of a surprising card trick. ${ }^{6}$ The second Web experiment was conducted to explore the development of implicit mathematical knowledge via estimations of length in the archimedic spiral (Krist \& Reips, 2001). In this study, we used the method of functional measurement (Anderson, 1982; Wilkening, 1979) and applied it to Web experimenting.

\section{ACCESS STATISTICS \\ AND LINKING DENSITY}

After the Web Experimental Psychology Lab had opened, it was advertised only with a link in the local newspaper's Web site. ${ }^{7}$ Soon (in January 1996), the German national magazine Der Spiegel discovered the site and put it on its "Top Ten" list. That hyperlink generated enough traffic and new linking to provide the Web Experimental Psychology Lab with a solid base for participation from a wide variety of locations. This variety is greater nowadays. The number of second-level domains of visitor IPs to our own Web experiments increased from 176 during August 1996 to 294 during August 1999. One of the reasons for this variety is the large number of hyperlinks that were set to the Web Lab-today, there are more than 1,000 links (Extreme Digital, 2001). Generally, a

\section{Referring Websites Aug.6 - Sept.6 '98}

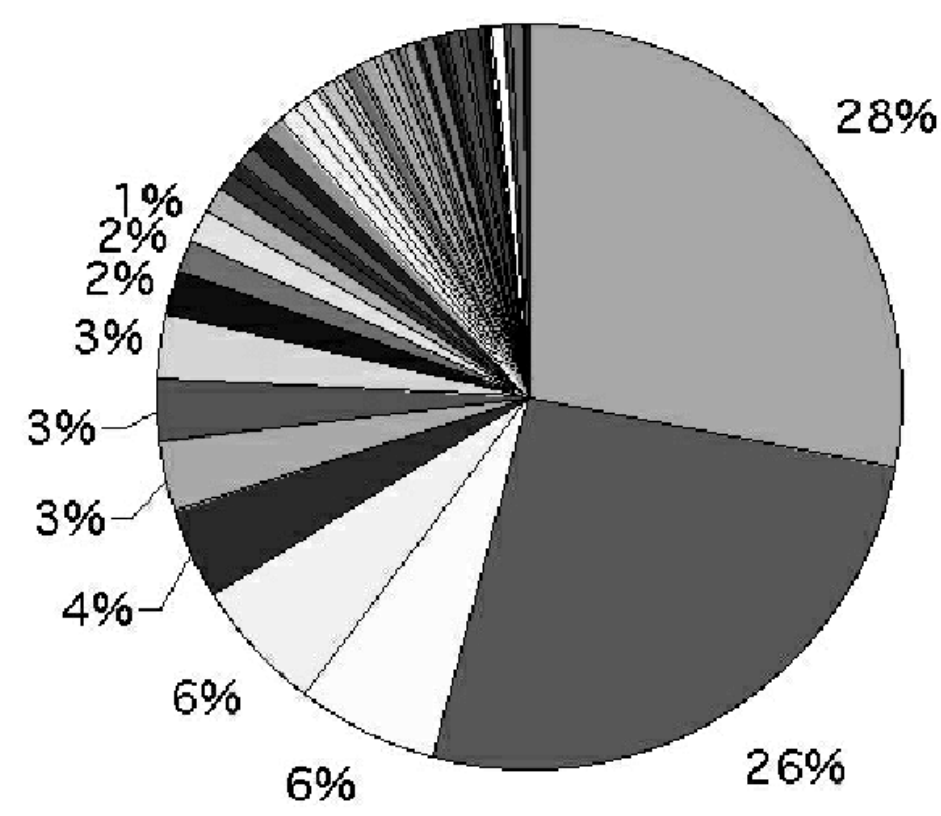

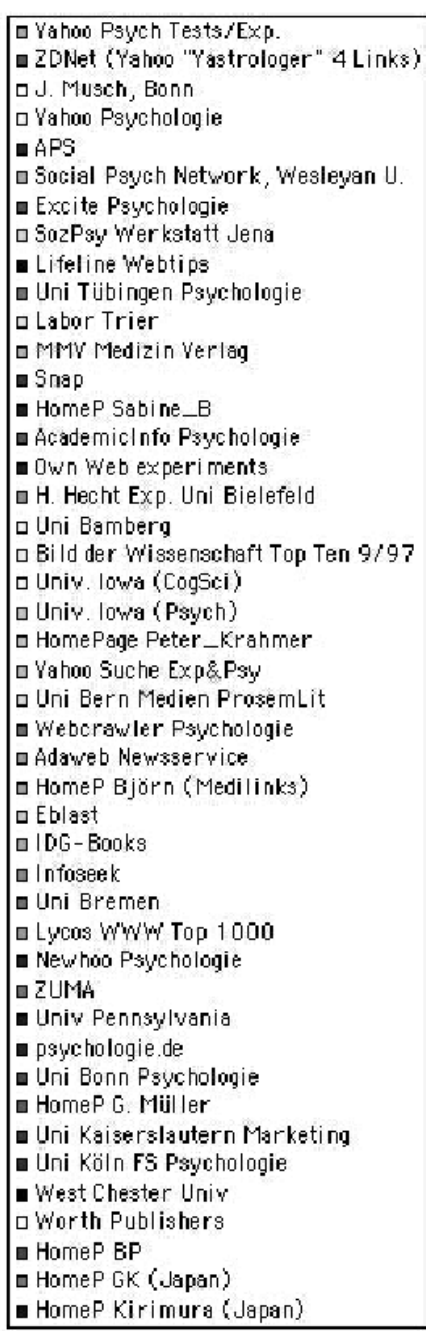

Figure 2. Top referring sites to the Web lab in August 1998 (the relative referring frequency decreases from the top to the bottom of list). 
greater number of hyperlinks from other sites will help in attracting a demographically diverse pool of visitors.

Figure 2 shows the top referring sites identified using a JavaScript routine during August 1998. Referrer information can be used for quasiexperimentalanalyses (Reips, 1997b, 2000). As can be seen in Figure 2, about half of the visitors to the Web Lab were referred from two Yahoo directory Web sites. The other half were surfing in from a multitude of small Web sites.

In 1998, the laboratory moved its physical base to the University of Zurich. Now, after 2 years, still more than half of the visitors first go to the old Web address at the University of Tübingen. They are forwarded from there via pages containing a HTML meta tag called "refresh." At last count, the laboratory registered an average of more than 4,000 visits per month (see Figure 3).

How to measure the number of participants? There has been an ongoing discussion of how to best measure the attention a Web site is getting. Different methods used are counts of (unique) hits, click-throughs, page impressions or page views, visits, and returns. In the Web Experimental Psychology Lab, we use Unix server logfile analysis of the main pages, JavaScript, and three of a number of free tracking services on the Internet-for example, WebTracker (FxWeb Web Technologies, 1999)_to get an estimate of true visits by people. Such an estimate is facilitated by the fact that the Web Lab is made up of un- framed static Web pages, to achieve the highest possible compatibility with a wide range of Web browsers.

In Figure 3, visits are single downloads of the plain (not the animated) entry pages to the Web Experimental Psychology Lab. To receive an estimate of true visits, these figures need to be corrected by subtracting robot visits and cases in which users switch between language versions, in which they reload the pages, in which their caches are turned off and they go back, and in which they return to the entry page at the end of an experiment (unless they went to the experiment directly). On the other hand, one has to add those cases in which people get the pages from proxy servers (this number has been increasing in recent years), in which they enter via a different URL (the most recently introduced one is http://www.genpsy. unizh.ch/Ulf/Lab/WebExpPsyLab.html), and in which several persons connect using the same IP addresses. On both the positive and the negative side, a few other cases are possible. Theoretically, estimates could also be based on figures for certain images and on figures for visits from certain IP addresses.

Of course, visits are not "people who have been in the Web Lab exactly one time." However, with the help of persistent cookies, it is possible to estimate quite accurately how many people return (about $80 \%$ do not; see Table 1) and how often. The cumulative statistics in Table 1 show that the total percentage of returns is decreasing over time.

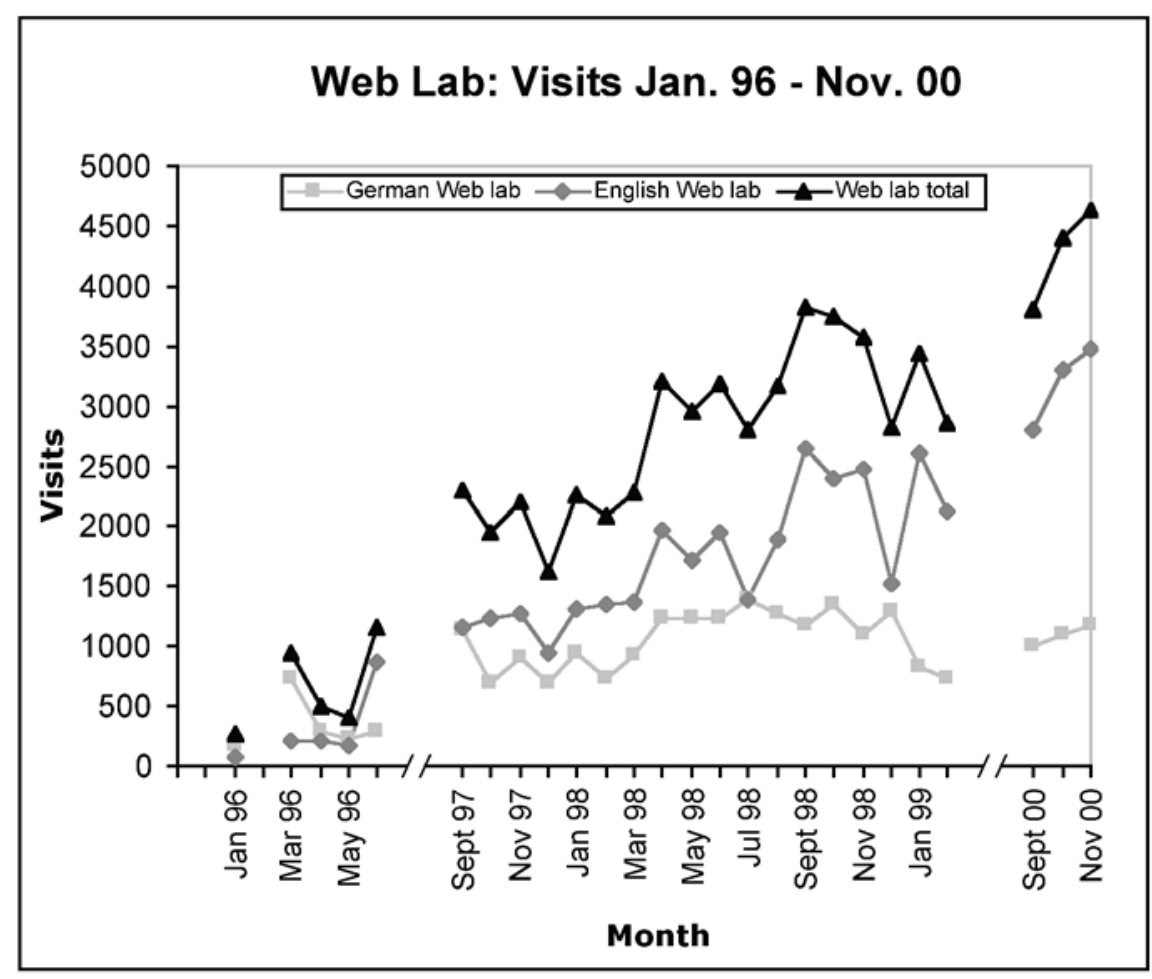

Figure 3. Visits to the Web lab, based on available statistics (September- November 2000 visit counts are estimates based on a different analytic method). 
Table 1

Return Frequency (in Percentages) by

Visitors to the Web Experimental Psychology

Lab, as Determined through Webtracker

(FxWeb Web Technologies, 1999) by Persistent Cookies

\begin{tabular}{ccccc}
\hline & \multicolumn{3}{c}{ Period Beginning 10/26/98 (Cumulative) } \\
\cline { 2 - 5 } Return Frequency & After 43 Days & After 289 Days & After 666 Days & After 766 Days \\
\hline None & 66 & 66 & 79 & 83 \\
1-2 Times & 27 & 23 & 14 & 12 \\
3-6 Times & 6 & 7 & 4 & 3 \\
7+ Times & 1 & 4 & 3 & 2 \\
\hline
\end{tabular}

This is a logical consequence of the increase in total number of visitors.

\section{Checklist: What to do to Attract Visitors}

Usually, a Web site needs to be promoted, since competition for the attention of Web surfers is fierce. There are now more than a billion indexable Web pages (Sullivan, 2000), and the rate at which their number is doubling is still increasing. Consequently, the minimum actions one should take to promote a research-oriented Web site are summarized in the following list: One should make the Web site attractive (nice graphics, good func- tionality, fast loading times); one should recognize that academic/nonprofit Web sites are better accepted than commercial ones; there should be off-line marketing and Web site promotion; one should have META tags; one should promote the Web site at search engines and Internet directories (including preparation of Web pages with keywords, submission, and checks of link popularity); and one should avoid changing URLs, since many links and traffic will be lost. Details about these procedures can be found on the Internet; some nice and simple guidelines can be found, for example, at http://robert_laws. tripod.com/stats.html.

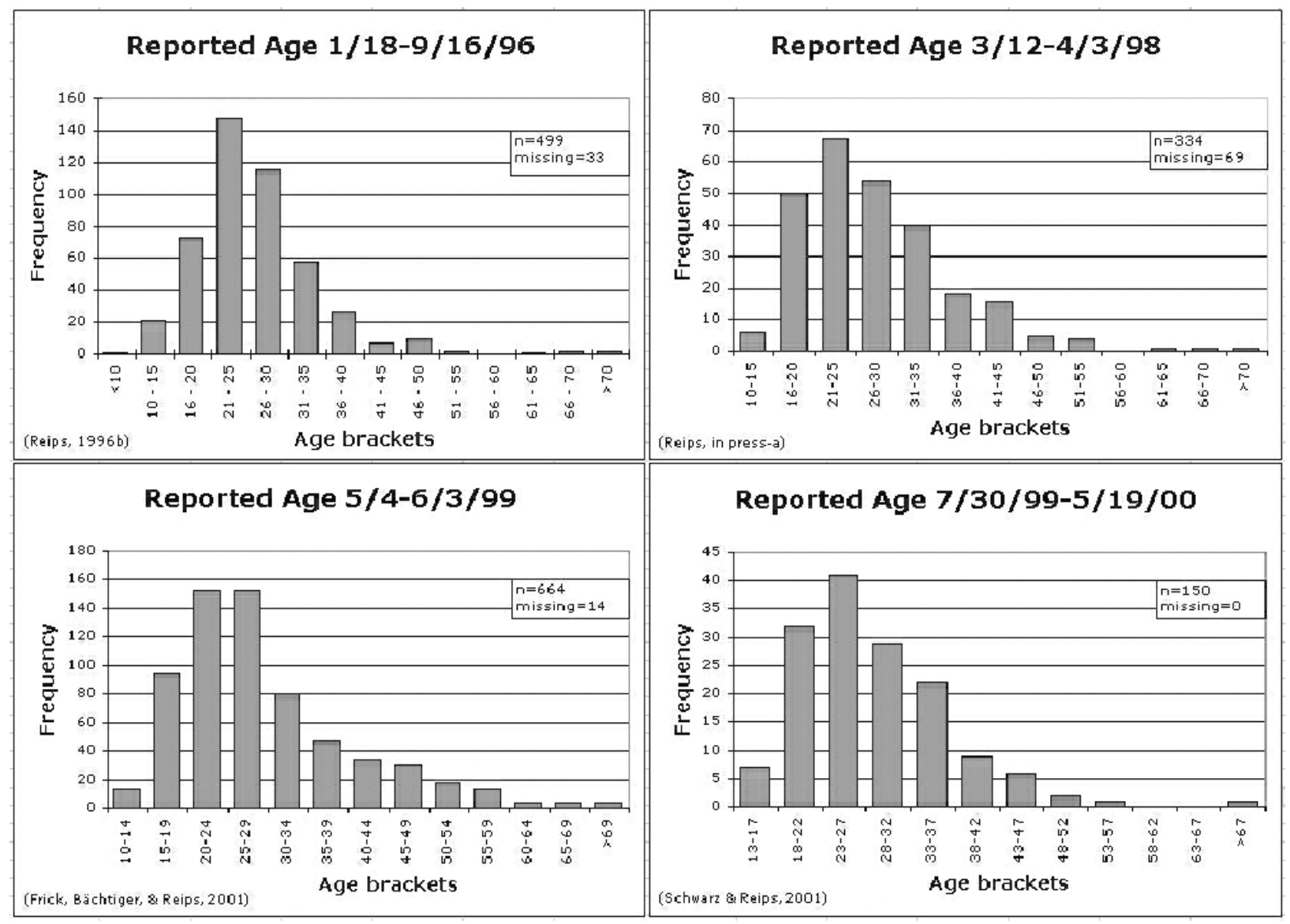

Figure 4. Reported visitor age in four Web experiments conducted in the Web Experimental Psychology Lab between January 1996 and May 2000 (from Frick, Bächtiger, \& Reips, 2001; Reips, 1996b, in press-a; Schwarz \& Reips, 2001). 


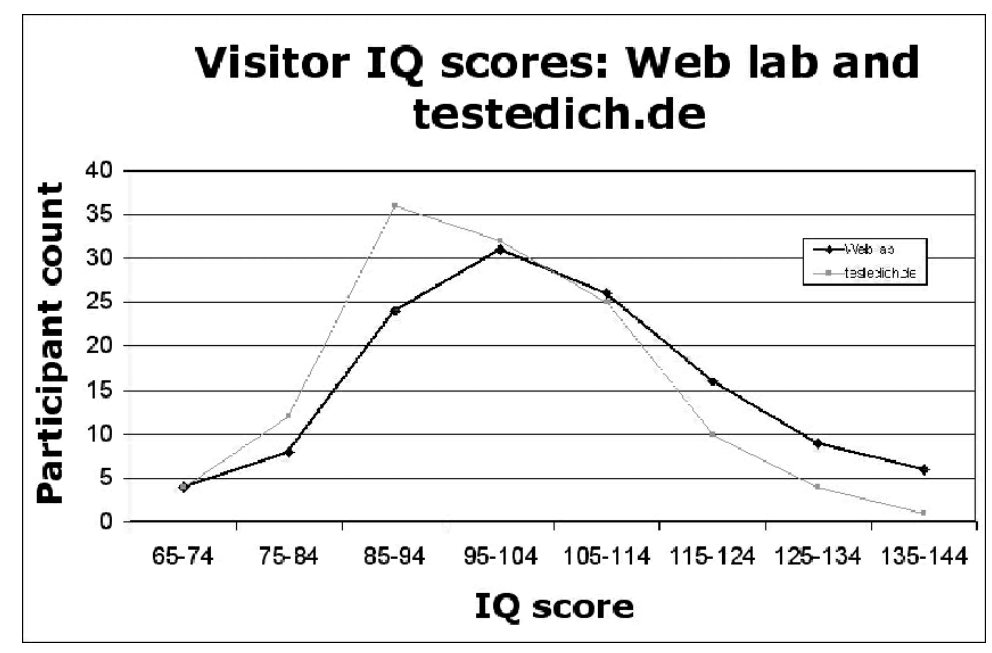

Figure 5. Web lab and testedich.de (a self-test Web site) visitor IQ scores. Scores were normed to the sample studied (i.e., the average score of all the participants was set to 100).

Visitor Demographics

Who is accessing the Web Experimental Psychology Lab? Over the years, participant demographics have been collected in a number of different Web experiments. These data show a remarkable consistency in visitor age (Figure 4). Gender distribution, on the other hand, has changed over the years and seems to reflect the general trend toward a high proportion of females on the Internet (Graphics, Visualization, and Usability Center, 1999).

Recently, Ralph Lengler and I conducted an on-line Web experiment on various aspects of administering an IQ test by Jäger, Süss, and Beauducel (1997). Two links to the Web experiment were placed: one in the Web Experimental Psychology Lab, and one on a Web site for selfadministering psychological tests (http://testedich.de). Figure 5 shows the IQ scores of the first 248 participants referred from these Web sites (124 from each). The distribution of IQ scores of the participants coming from the Web lab is close to normal. Consequently, arguments based on IQ distribution can hardly be used in reasoning against the generalizability of results from studies conducted in the Web Lab to the general population.

\section{Logfile Analysis}

One basic principle in behavioral research is the collection and storage of raw data. In on-line research, this means reliance on logfiles, not only on aggregated data. Web server logfiles contain information about a number of actions performed by a participant that might be important when (re)analyzing the data. Typical information contained in a logfile includes the following:

DATE: The date, at the server location;

TIME: The time, see date;

RESULT: Shows whether an error occurred during the file transfer;

HOSTNAME: Name of the user's computer;
URL: "Universal Resource Locator," the retrieved file's address on the web server; BYTES_SENT: The size of the file transferred; AGENT: The web browser used by the user; REFERER: The web page the user was referred from; TRANSFER_TIME: Length of time used for the file transfer;

SEARCH_ARGS: Information provided by the user on the web page, sometimes hidden.

The information listed above can be used to determine drop-out and compliance rates, response times, behavioral data (choices, verbal responses, mouse movement, site navigation patterns, etc.), and other information. For example, response times can be calculated by taking the difference between the TIME when a document was accessed and the TIME the next document was accessed, corrected by the TRANSFER_TIME. This is a rather crude measure of response times, but it may suffice for some purposes. Better assessment of response times can be achieved through the use of JavaScript or Java. Although the reliability of "reaction times" in Web studies is questionable for reasons inherent in the nature of the Internet, it has been shown that differences in reaction times found in laboratory experiments can be replicated surprisingly well in Web experiments (Reips, Morger, \& Meier, 2000). Eichstaedt (2001) describes and evaluates a Java-based technique for Web-based reaction time measurement.

\section{HARDWARE AND SOFTWARE}

This section contains a description of the laboratory's technical setup and a schematic description of its core components.

Technically, the Web Experimental Psychology Lab runs on an Apple-Unix mix of machines, with a rationale 
based on security and methodological considerations. Only the Web Experimental Psychology Lab's entry pages always remained on the universities' Unix servers, to guarantee a permanent URL and constant "up time." The main part of the Web Experimental Psychology Lab, as well as most of our own Web experiments, is run on an Apple Macintosh. Apple Web servers have been shown to offer the highest security, whereas Unix servers and Windows NT servers are easy prey for hackers (e.g., Dickey, 1999). Consequently, until the situation changes substantially, ethical standards for scientific research are best applied if participants' data are stored on an Apple system to ensure confidentiality.

For years, the Web server was run as a background application on the author's regular office computer, a Centris 610 . At that time, the whole building of the psychology department in Tübingen had only a $64 \mathrm{~K} / \mathrm{sec}$ connection to the Internet, proving that this bandwidth can be sufficient for conducting Web experiments. Nowadays, the Web server is a stand-alone Powermac administered remotely via Timbuktu (a screen-sharing application). Bandwidth at the Zurich location is $256 \mathrm{~K} / \mathrm{sec}$ to the university server, and the university server stands right on the European East- West Internet backbone.

The Web server application used is WebStar, formerly MacHTTP. WebStar has been and continues to be the leading Web server application on the Macintosh platform. Only one additional software piece has been used from the very beginning of Web experimenting in the Web Lab: a freeware CGI program called "Redirect" that was written in the PocketForth programming language to ran- domly choose from a list of local or remote URLs. Its author, Ron Kneusel, is gratefully acknowledged for customizing the CGI for the Web Lab in 1995.

Figure 6 shows the Web Lab's hardware and software components. Recently, it became possible for the logfile analysis to be largely automated, using a self-developed Perl script. However, logfiles and Web experiment data are still always examined by the human eye and brain also, and the raw logfiles are kept for potential reanalyses.

\section{EXISTING WEB LABORATORIES}

Since the founding of the Web Experimental Psychology Lab in 1995, a host of other Web-based experimental laboratories have been established (listing in chronological order):

Interactive CyberLab for Decision-Making Research (http://www.etl.go.jp/ e6930) [April, 1996];

Laboratory of Social Psychology Jena (http://www. uni-jena.de/ ssw/labor.htm) [June, 1996];

Experimental Server Trier (http://cogpsy.uni-trier. de:8000/TEServ-e.html) [June, 1997];

Max-Planck Institute for Biological Cybernetics Tübingen (http://exp.kyb.tuebingen.mpg.de/Webexperiment/index.html) [November, 1997, currently disconnected];

Online Psychology Lab Padua (http://www.psy. unipd.it/personal/laboratorio/surprise/htmltesi/ind ex.html) [May, 1997];

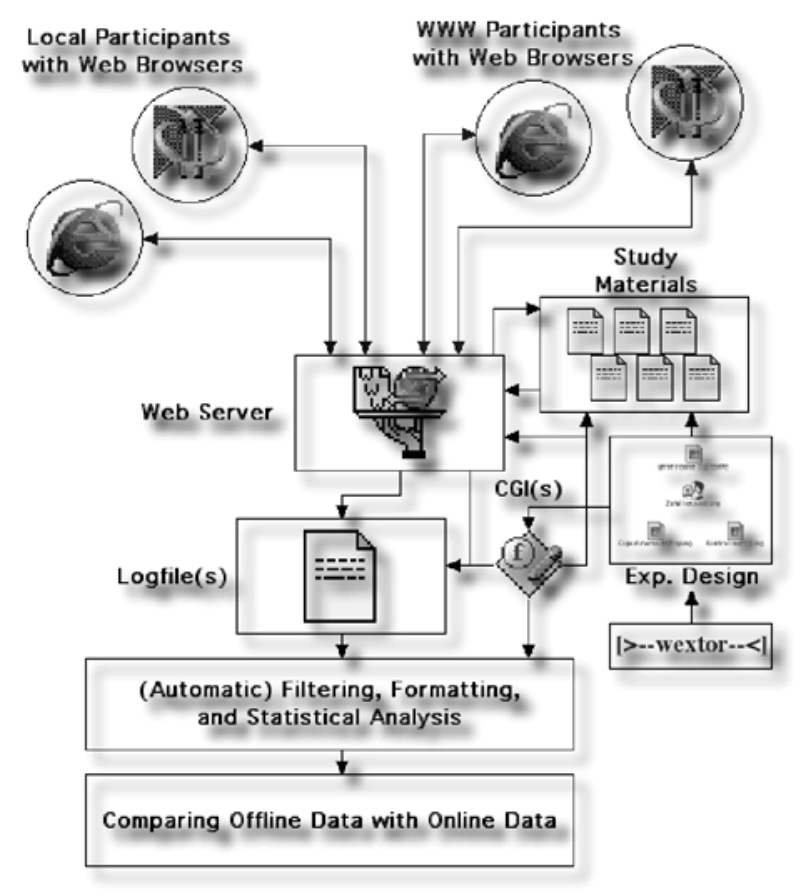

Figure 6. Chart of hardware and software components of the Web Lab. 
Decision Research Center (http://psych.fullerton.edu/ mbirnbaum/dec.htm) [started online experiments in March, 1998];

ZUMA Online-Labor (http://www.or.zuma-mannheim. de/inhalt/onlinelabor/Default.htm) [May, 1998];

Psycholinguist Laboratory Scotland (http://surf.to/ experiments) [September, 1998];

Psylab (http://www.uni-bielefeld.de/ psylab/index. html) [January, 2001].

All of the laboratories in the list above are used predominantly for experimental data collection. Further Web experiments can be assessed on the Web experiment list (http://www.genpsy.unizh.ch/Ulf/Lab/webexplist. $\mathrm{html}$ ), on the classical Web site by the American Psychological Society (http://psych. hanover.edu/APS/exponnet. html), and on William E. Snell Jr.'s Web site that accompanies his introductory psychology class on Psychological Perspectives on Human Behavior (http://psychology2. semo.edu/websites/web41.htm).

Some additional WWW laboratories, such as the Internet Psychology Lab (http://kahuna.psych.uiuc.edu/pl/), engage in the teaching or demonstration of experiments. This site went on line in April, 1998. Another demonstration site, the Cognitive Psychology Online Laboratory (http://coglab.psych.purdue.edu/coglab/) opened in the fall of 1997 (Francis, Neath, \& Surprenant, 2000). The PsychExps on-line laboratory (http://www.olemiss.edu/ PsychExps [opening in fall 1998]) offers a combination: It is a Web site dedicated to data collection for teaching purposes (McGraw, Tew, \& Williams, 2000).

\section{DATA QUALITY}

Data quality in online-research can be checked and ensured by using a number of techniques (Musch \& Reips, 2000; Reips, 1997b, 2000; Schmidt, 2000). These techniques, as well as logfile analysis tools, can help with the detection of multiple submissions and inaccurate statements and with the prevention of garbage data.

In Internet science, one cannot easily draw the conclusion that independence of observations is guaranteed. Undetected multiple submissions could occur if people were to $\log$ in twice from different computers (probably a rare case; see Reips, 1997b, 2000) or, increasingly more likely, be assigned different IPs through dynamic addressing. Therefore, checking for multiples by using a more conservative combination of IP and e-mail address might be a reliable alternative, since e-mail addresses can be checked for validity and can be used for determining true percentage of "individualidentities," using such measures as the subsampling technique (Reips, 1997b, in press-b).

In an on-line laboratory with several studies, users might participate in more than one study. In principle, this information can be tracked (e.g., through the use of so-called cookies $^{8}$ ). As Table 1 shows, currently about $80 \%$ of visitors do not return to the Web Experimental Psychology Lab within 22 months, making it unlikely that they take part in more than one of the Web experiments (at least, less likely than psychology students' participating in more than one university laboratory experiment).

One important principle in the administration of a virtual laboratory is establishing and supporting the user's involvement. Visitors can be asked to give feedback. Basically, on the Internet this can be achieved through e-mail or WWW forms (e.g., as short pop-up surveys). However, participants will not necessarily use the communication opportunities provided, despite their ease of use on the Internet. ${ }^{9}$ Consequently, only a very motivating wording of the request for feedback or additional measures (e.g., a lottery of incentives among respondents) might generate a satisfying feedback rate.

In the Web Experimental Psychology Lab, every experimental slot contains a mailto-hyperlink with a predefined experiment identifier for contacting the principal researcher and the Web Lab administration. Also, we place e-mail addresses and, sometimes, mailing addresses on the introductory and end pages of our own Web experiments. E-mails by visitors can help in the detection of problems - for example, in cases in which a Web experiment cannot be accessed.

Optimal laboratory design includes data security. As was mentioned before, operating systems and Web server applications differ in this regard. Therefore, a virtual laboratory's setup needs careful planning to protect visitors' privacy according to ethical guidelines for conducting scientific research (see American Psychological Association, 1992). As far as we know, there has never been a successful attempt to break into the Web Experimental Psychology Lab's server or otherwise tamper with participants' personal information or data.

\section{OUTLOOK}

During the 5 years of its existence, the Web Experimental Psychology Lab has seen different eras of the Internet. After a continuous increase in Web experiments, as well as in visitors, the number of visitors might begin to stagnate at some point in time. A possible reason to predict such a development might be the increased competition for Web users interested in psychological testing and experimenting, since many Web sites geared toward this group have recently sprung up. So far, the Web Experimental Psychology Lab's largely unchanged design and technology have proven to remain attractive to Web masters responsible for creating new hyperlinks. However, the time has come for a redesign of the Web Experimental Psychology Lab. New features will include a version made with frames and rollover animations, a passwordprotected section with personalized information, and a virtual course on Web experimenting, including information on experimental psychology written to hopefully heighten laypersons' understanding of what we are doing. In addition, the archive will be expanded to include raw data for reanalysis and open peer commentary (see Psycoloquy, 2000). Recently, we developed a Javascript-based 
Web experiment generator named WEXTOR. ${ }^{10}$ WEXTOR can be used to build Web experiments in a guided stepby-step process. It dynamically creates the custom-tailored Web pages and Javascripts needed for the Web experiment, and it provides the experimenter with a print-ready visual display of one's experimental design, in terms of directories (folders) and Web pages. These Web experiments can then be conducted in the Web Experimental Psychology Lab.

The Web Experimental Psychology Lab is bound to stand, serving the scientific community with a virtual place to conduct and archive Web experiments. As before, it will house Web experiments from various fields, with a special effort to advance research conducted to refine the Web experimental method.

What will the future structure of experimental Internet science be like? Undoubtedly, we will see a further increase in the number of small Web labs and single studies advertised individually. Many university departments will run laboratories for their own on-line data collection. However, since the Internet allows for distributed research, "real-world" institutional affiliations might dissolve, to be replaced by virtual places for scientific cooperationsuch as the Web Experimental Psychology Lab.

\section{REFERENCES}

American Psychological Association (1992). Ethical principles of psychologists and code of conduct [on-line document]. Available: http://www.apa.org/ethics/code.html. [Retrieved April 6, 2001]

ANDERSON, N. H. (1982). Methods of information integration theory. New York: Academic Press.

Birnbaum, M. H. (1999). How to show that $9>221$ : Collect judgments in a between-subjects design. Psychological Methods, 4, 243-249.

Birnbaum, M. H. (2000). Psychological experiments on the Internet. San Diego: Academic Press.

Booth-Kewley, S., EDWARdS, J., \& Rosenfeld, P. (1992). Impression management, social desirability, and computer administration of attitude questionnaires: Does the computer make a difference? Journal of Applied Psychology, 77, 562-566.

Buchanan, T., \& Smith, J. L. (1999). Using the Internet for psychological research: Personality testing on the World Wide Web. British Journal of Psychology, 90, 125-144.

Connes, B. (1972). The use of electronic desk computers in psychological experiments. Journal of Structural Learning, 3, 51-72.

DicKey, C. E. (1999). Web page hacker arrested, government sites becoming more secure [On-line document]. Available: http://www.dtic. mil/armylink/news/Sep 1999/a19990901 hacker.html. [Retrieved April 6, 2001]

EICHSTAEDT, J. (2001). An inaccurate-timing filter for reaction time measurement by JAVA applets implementing Internet-based experiments. Behavior Research Methods, Instruments, \& Computers, 33 179-186.

Extreme Digital (2001). Extreme tracking [On-line document]. Available: http://www.extreme-dm.com/tracking/. [Retrieved April 6, 2001]

Francis, G., Neath, I., \& Surprenant, A. (2000). The Cognitive Psychology Online Laboratory. In M. H. Birnbaum (Ed.), Psychological experiments on the Internet (pp. 267-283). San Diego: Academic Press.

Frick, A., BÄchtiger, M. T., \& ReIPS, U.-D. (2001). Financial incentives, personal information, and drop out in online studies. In U.-D. Reips \& M. Bosnjak (Eds.), Dimensions of Internet science (pp. 209220). Lengerich: Pabst.

FXWeb Web Technologies (1999). Webtracker version 2 [On-line document]. Available: http://www.fxWeb.com/tracker/. [Retrieved April 6, 2001]
Graphics, Visualization, and Usability Center (1999). GVU's WWW user surveys [on-line document]. Available: http://www.cc. gatech.edu/gvu/user_surveys. [Retrieved April 6, 2001]

HÄnze, M., \& Meyer, H. A. (1997). Feldexperimente und nicht-reaktive Messung im World Wide Web [Field experiments and nonreactive measurement on the World-Wide Web]. In D. Janetzko, B. Batinic, D. Schoder, M. Mattingley-Scott, \& G. Strube (Eds.), CAW-97. Beiträge zum Workshop "Cognition \& Web" (pp. 141-148). Freiburg, Germany: IIG-Berichte 1/97.

Hewson, C. M., Laurent, D., \& Vogel, C. M. (1996). Proper methodologies for psychological and sociological studies conducted via the Internet. Behavior Research Methods, Instruments, \& Computers, 28, 186-191.

Hoffman, R., \& MacDonald, J. (1993). Using HyperCard and Apple events in a network environment: Collecting data from simultaneous experimental sessions. Behavior Research Methods, Instruments, \& Computers, 25, 114-126.

HogGatT, A. C. (1977). On the uses of computers for experimental control and data acquisition. American Behavioral Scientist, 20, 347-365.

Jäger, A. O., SÜsS, H.-M., \& BEAuducel, A. (1997). Berliner Intelligenzstruktur-Test (BIS-Test): Form 4 [The Berlin Intelligence Structure Test: Form 4]. Göttingen: Hogrefe.

JANETZKo, D. (1999). Statistische Anwendungen im Internet [Statistical applications for the Internet]. Munich: Addison-Wesley.

KIELEY, J. M. (1996). CGI scripts: Gateways to World-Wide Web power. Behavior Research Methods, Instruments, \& Computers, 28, 165-169. Krantz, J. H., Ballard, J., \& SCHER, J. (1997). Comparing the results of laboratory and World-Wide Web samples on the determinants of female attractiveness. Behavior Research Methods, Instruments, \& Computers, 29, 264-269.

KRIST, H., \& REIPS, U.-D. (2001). Length estimation in the archimedic spiral: Studying information integration on the Internet. Manuscript in preparation.

McGraw, K. O., Tew, M. D., \& Williams, J. E. (2000). An online psychology laboratory. In M. H. Birnbaum (Ed.), Psychological experiments on the Internet (pp. 219-233). San Diego: Academic Press.

Morrow, R. H., \& McKeE, A. J. (1998). CGI scripts: A strategy for between-subjects experimental group assignment on the World-Wide Web. Behavior Research Methods, Instruments, \& Computers, 30, 306-308.

Musch, J., \& REIPS, U.-D. (2000). A brief history of Web experimenting. In M. H. Birnbaum (Ed.), Psychological experiments on the Internet (pp. 61-85). San Diego: Academic Press.

Psycoloquy (2000). [On-line document]. Available: http://www. princeton. edu/ harnad/psyc.html. [Retrieved April 6, 2001]

ReIPS, U.-D. (1995). The Web experiment method [On-line document]. Available: http://www.genpsy.unizh.ch/Ulf/Lab/WWWExpMethod html. [Retrieved April 6, 2001]

REIPS, U.-D. (1996a, April). Experimentieren im World-Wide Web [Experimenting in the World-Wide Web] [Abstract]. Experimentelle Psychologie: Tagung experimentell arbeitender Psychologen [Proceedings of the Experimental Psychologist's Conference], 38, 256-257.

ReIPS, U.-D. (1996b, October). Experimenting in the World Wide Web. Paper presented at the 1996 Society for Computers in Psychology Conference, Chicago. Available: http://www.genpsy.unizh.ch/reips/ slides/scipchicago96.html. [Retrieved April 6, 2001]

REIPS, U.-D. (1997a). Forschen im Jahr 2007: Integration von WebExperimentieren, Online-Publizieren und Multimedia-Kommunikation [Science in the year 2007: Integration of Web experimenting, online publishing, and multimedia communication]. In D. Janetzko, B. Batinic, D. Schoder, M. Mattingley-Scott, \& G. Strube (Eds.), CAW-97: Beiträge zum Workshop “Cognition \& Web” (pp. 141-148). Freiburg, Germany: IIG-Berichte 1/97.

REIPS, U.-D. (1997b). Das psychologische Experimentieren im Internet [Psychological experimenting on the Internet]. In B. Batinic (Ed.), Internet für Psychologen (pp. 245-265). Göttingen: Hogrefe.

REIPS, U.-D. (1999). Online research with children [On-line book]. In U.-D. Reips, B. Batinic, W. Bandilla, M. Bosnjak, L. Gräf, K. Moser, $\&$ A. Werner (Eds.), Current Internet Science-trends, techniques, results/Aktuelle Online Forschung-Trends, Techniken, Ergebnisse. 
Zurich: Online Press. Available: http://dgof.de/tband99/. [Retrieved April 6, 2001]

ReIPS, U.-D. (2000). The Web experiment method: Advantages, disadvantages, and solutions. In M. H. Birnbaum (Ed.), Psychological experiments on the Internet (pp. 89-114). San Diego: Academic Press. REIPS, U.-D. (in press-a). Context effects in Web surveys. In B. Batinic, U.-D. Reips, \& M. Bosnjak (Eds.), Online social sciences. Seattle: Hogrefe \& Huber.

ReIPS, U.-D. (in press-b). Theory and techniques of Web experimenting. In B. Batinic, U.-D. Reips, \& M. Bosnjak (Eds.), Online social sciences. Seattle: Hogrefe \& Huber.

ReIps, U.-D., Morger, V., \& MeIer, B. (2000). Fünfe gerade sein lassen: Listenkontexte [Letting five be equal: List contexts]. Manuscript submitted for publication.

SchmidT, W. C. (2000). The server-side of psychology Web experiments. In M. H. Birnbaum (Ed.), Psychological experiments on the Internet (pp. 285-310). San Diego: Academic Press.

SchWARZ, S., \& REIPS, U.-D. (2001). CGI versus JavaScript: A Web experiment on the reversed hindsight bias. In U.-D. Reips \& M. Bosnjak (Eds.), Dimensions of Internet science (pp. 75-90). Lengerich: Pabst.

Sullivan, D. (2000, July 7). Search engine sizes [On-line]. Available: http://searchenginewatch.com. [Retrieved April 6, 2001]

WASON, P. C. (1968). Reasoning about a rule. Quarterly Journal of Experimental Psychology, 20, 273-281.

WiLKENING, F. (1979). Combining of stimulus dimensions in children's and adults' judgments of area: An information integration analysis. Developmental Psychology, 15, 25-33.

\section{NOTES}

1. http://www.genpsylab.unizh.ch or http://www.genpsy.unizh.ch/ Ulf/Lab/WebExpPsyLab.html.

2. Undercover or hidden Web experiments are conducted by manipulating existing Web sites or creating Web sites without experimentrelated content with the intention of conducting an experiment. Visitors are not aware of their participation.

3. http://www.genpsy.unizh.ch/Ulf/Lab/WebLabDokuE.html.

4. http://www.genpsy.unizh.ch/Ulf/Lab/WebLabCond.html.

5. http://www.genpsy.unizh.ch/forschung/kidslab/labone.html

6. http://www.genpsylab.unizh.ch/archive/88496/magic.htm.

7. http://www.cityinfonetz.de/aktuell/links/00.html.

8. A Cookie is a unique string of letters and numbers that the Web server stores in a file on a visitor's hard drive. This method is used by Web designers to track visitors to a Web site.

9. For example, Tom Buchanan (personal communication, September $19,2000)$ received only 41 responses across three studies (combined $N=6,518$ ) in which people wishing to give feedback had the option of filling in a form and zero responses in a comparable study $(N=1,700)$ where only a mailto link was provided.

10. http://www.genpsylab.unizh.ch/wextor/index.html.

(Manuscript received December 8, 2000; revision accepted for publication March 21, 2001.) 